\title{
Delayed extinction of escape responses: A parametric study'
}

\author{
Kenneth B. Melvin, UNIVERSITY OF ALABAMA
}

R. Chris Martin, UNIVERSITY OF KENTUCKY

Gary Parsons, UNIVERSITY OF FLORIDA

\begin{abstract}
Five groups of seven rats each were subjected to delay periods of $1,6,18,54$, or $162 \mathrm{~min}$. between the last trial of shock-escape training and the initial trial of extinction. Median number of trials to extinction was a negatively accelerated decreasing function of length of delay. Increased delay also led to slower starting and running speeds over trials.
\end{abstract}

\section{Introduction}

While conditioned responses may be retained over months or years, some loss in response strength usually appears when Ss are retested (Kimble, 1961). Estes (1955) has termed this loss "spontaneous regression." Little is known about this phenomenon despite its theoretical importance and its methodological significance for the study of extinction.

In aversive conditioning, the lone parametric study using extinction measures is that of Moyer (1958), who found no significant differences among groups as a function of duration of delay between the termination of avoidance training and the initial extinction trial. The effects of short-term delays between the last training trial and the first extinction trial in an escape-learning situation were examined in the present study. An escape situation was preferred to an avoidance one because of the lack of control of shock presentation inherent in avoidance situations.

\section{Subjects}

The Ss were 35 naive male hooded rats of the LongEvans strain, 70-100 days old when first introduced into the apparatus. They were randomly assigned to five equal-sized groups and run in seven replications. Throughout the study, Ss were housed in individual cages and maintained on an ad lib diet of Purina Laboratory Chow and water.

\section{Apparatus}

The apparatus consisted of starting box, a $4 \mathrm{ft}$ straight alley, and a goal box. Start box and alley had grid floors and glass lids, the goal box, a wooden floor and lid. A trap-door floor, hinged along one edge, 7 in above the grid floor, divided the start box into upper and lower compartments. The $S$ was placed in the upper compartment through a hinged door at the rear. A guillotine door at the entrance to the goal box prevented retracing. Further details of the apparatus may be found in Brown et al (1964).

Shock (60 cycles a.c.) was delivered to the grid by variable voltage auto-transformer through a $10 \mathrm{~K} \mathrm{ohm}$ series resistor. Through the use of photocells and associated electronic equipment, response times were measured to the nearest .01 sec.Starting time was taken as the time that elapsed between the release of the trap door and the interruption of a light beam located at the junction between the start box and alley. Alley time was the time separating the interruption of the first beam and a second located at the entrance to the goal box.

\section{Procedure}

Prior to introduction into the apparatus, $\mathrm{S}$ was handled for a few minutes on two separate occasions during the preceding $48 \mathrm{hr}$. Three preliminary training trials were given in the following manner: 1 to $6 \mathrm{sec}$. after the guillotine door was raised, $\mathrm{S}$ was manually dropped onto the electrified (50 v open-circuit voltage) grid about $1.5 \mathrm{ft}$ from the goal box. A wooden barrier $2 \mathrm{ft}$ from the goal box prevented the rat from running toward the start box. Upon entry into the goal box, the guillotine door was lowered and $\mathrm{S}$ remained in the goal box for $30 \mathrm{sec}$.

On the next 12 trials (training), $\mathrm{S}$ was inserted into the upper section of the start box. One to 6 sec. after the guillotine door was raised, the trap-door was released, dropping $S$ onto the grid floor $(60 \mathrm{v})$ below. When the rat entered the goal box the door was lowered and response times recorded.

Following the last training trial (which included $30 \mathrm{sec}$. in the goal box), $\mathrm{S}$ was placed in his home cage for either $1,6,18,54$, or $162 \mathrm{~min}$. After this delay, extinction trials were conducted. The extinction procedure duplicated acquisition except for the omission of shock. If an animal failed to enter the goal box within $60 \mathrm{sec}$., extinction was discontinued and an arbitrary score of $60 \mathrm{sec}$. recorded.

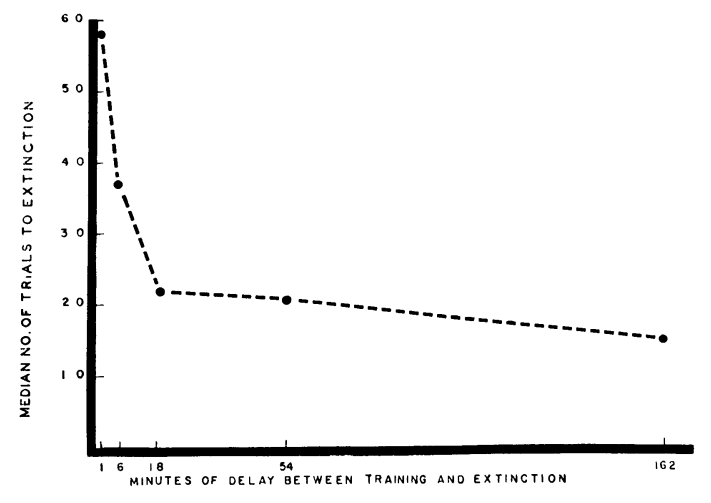

Fig. 1. Median number of trials to extinction as a function of delay (min.) between training and extinction. 


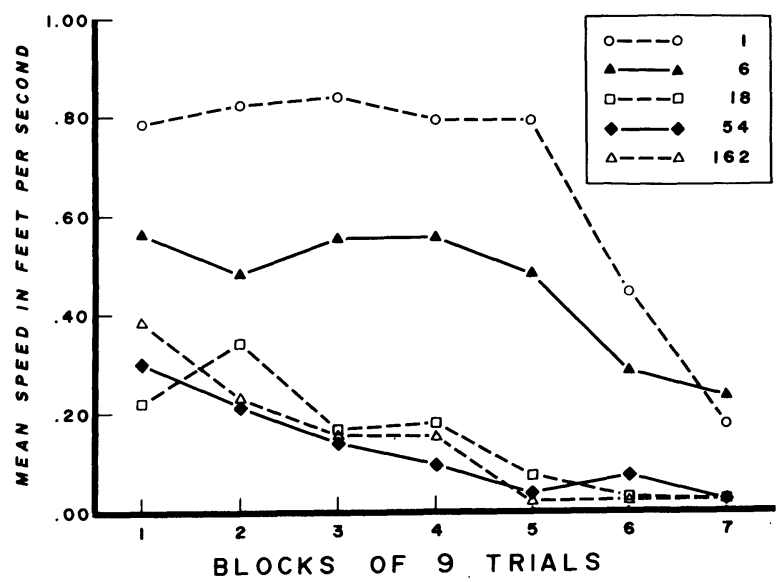

Fig. 2. Mean starting speed in $\mathrm{ft} / \mathrm{sec}$. over blocks of nine trials during extinction.

\section{Results}

The median number of trials to extinction for each of the five groups is shown in Fig. 1. As delay between training and the start of extinction increased, median number of trials to extinction was found to decrease. After 18 min. of delay, however, little further decrease in resistance to extinction is seen. A Kruskal-Wallis one-way analysis of variance of the median number of trials to extinction for the five groups yielded an $\mathrm{H}$ of $12.54(\mathrm{p}<.02)$.

Figure 2 presents starting speed for the five groups over blocks of nine trials. These data indicate that starting speed is a decreasing function of delay between acquisition and extinction. The superiority of the 1 and 6 min. groups over the others is striking. An analysis of variance performed on the speed scores (in $\mathrm{ft} / \mathrm{sec}$. obtained by multiplying the reciprocal of S's median running time for a block of nine trials by a constant) established the Delay treatment effect as significant $(F=7.20 ; d f=4 / 30 ; p<.01)$. The Trials effect $(F=17.35$; $\mathrm{df}=6 / 180 ; \mathrm{p}<.001$ ) and the interaction of Trials by Treatment $(F=1.81 ; \mathrm{df}=24 / 180 ; \mathrm{p}<.02)$ were also found to be statistically significant.

Alley speeds over nine-trial blocks are shown in Fig. 3. Again, extinction performance decreases as a function of delay. An analysis of variance revealed that the Delay treatment effect approached significance $(F=2.14 ; d f=4 / 30 ; p=.10)$. Interaction was not significant.

\section{Diseussion}

Our results indicate that the resistance to extinction of an escape response is a negatively accelerated decreasing function of the delay between acquisition and extinction. Further diminution with increasing delay fails to occur beyond $1 \mathrm{hr}$. for speed measures. This

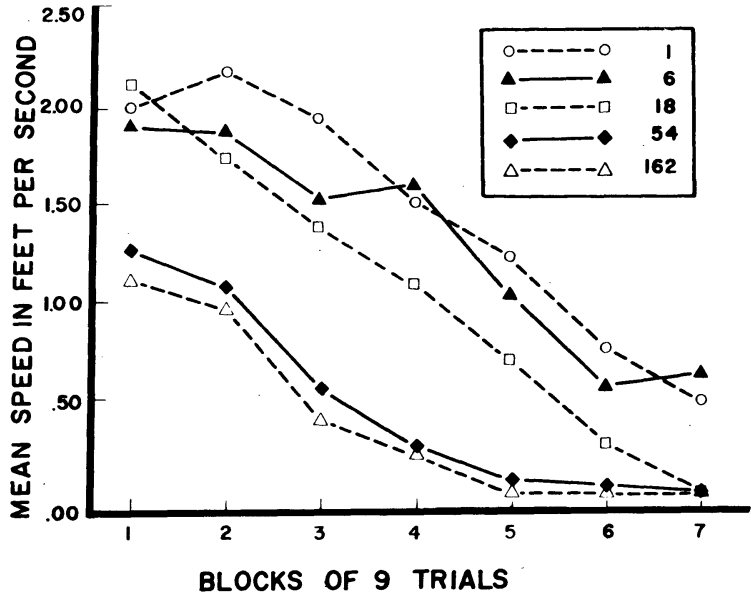

Fig. 3. Mean alley speed in $\mathrm{ft} / \mathrm{sec}$. over blocks of nine trials during extinction.

leveling off occurs even earlier for number of trials to extinction. The methodological implications of these data are clear; Es desiring strong resistance to extinction of escape responses should schedule the first extinction trials immediately after the last training trial, or at least within $10 \mathrm{~min}$. of it.

A possible theoretical explanation of the delay gradient might assume that noxious stimuli elicit internal responses which serve to energize the organism beyond the cessation of actual stimulation. These perseverating internal responses, termed "residual emotionality" by Siegel \& Siegel (1949), dissipate with passage of time, thus lowering drive and, consequently, performance during extinction. For the $1 \mathrm{~min}$. and $6 \mathrm{~min}$. groups (and possibly the $18 \mathrm{~min}$. group) drive level is determined by conditioned fear and residual emotionality. In the 54 and $162 \mathrm{~min}$. groups, however, residual emotionality would have largely dissipated, and the delay function becomes asymptotic.

References

BROWN, J. S., MARTIN, R. C., \& MORROW, M. W. Self-punitive behavior in the rat: Facilitative effects of punishment on resistance to extinction. J. comp. physiol. Psychol., 1964, 57, 127-133. ESTES, W. K. Statistical theory of spontaneous recovery and regression. Psychol. Rev., 1955, 62, 145-154.

KIMBLE, G. A. Hilgard and Marquis' conditioning and learning. New York: Appleton-Century-Crofts, 1961.

MOYER, K. E. Effect of delay between training and extinction on the extinction of an avoidance response. J. comp. physiol. Psychol. $1958,51,116-118$.

SIEGEL, P. S., \& SIEGEL, HELEN S. The effect of emotionality on the water intake of the rat. J. comp. physiol. Psychol., 1949, $42,12-16$

Nete

1. The research was supported in part by the University of Florida and the Wenner-Gren Aeronautical Research Laboratory, University of Kentucky. The authors are indebted to Bradford N. Bunnell for advice and Ss. 